\title{
POLÍTICAS PÚBLICAS DE ESPORTE NO MERCOSUL: GOVERNO ELETRÔNICO E CIDADANIA
}

\author{
PUBLIC POLICIES FOR SPORT IN MERCOSUR: ELECTRONIC GOVERNMENT \\ AND CITIZENSHIP
}

POLÍTICAS PÚBLICAS DE DEPORTE EN EL MERCOSUR: GOBIERNO ELECTRÓNICO Y CIUDADANÍA

Hosana Larissa Guimarães Oliveira*, Augusto Cesar Rios Leiro*
Palavras-chave

Políticas públicas.

Esportes.

Acesso à

informação.
Resumo: Esta pesquisa objetivou discutir a gestão do esporte nos países do Mercosul pela lente dos governos eletrônicos (e-Gov). Foi realizada pesquisa documental nos e-Gov de esporte dos dez países do Mercosul. Os dados foram analisados a partir das dimensões do esporte que orientam as ações do Estado e os e-Gov a partir dos seus níveis de informação, comunicação, serviço e participação. Os resultados indicaram que são diversos os interesses que levam o Estado a intervir no esporte, que a informação é colocada em diferentes níveis de qualidade e quantidade em cada país e que o controle democrático ainda é limitado.
Keywords

Public Policies.

Sports.

Access to

information.
Abstract: This study discusses sports management in Mercosur member-countries through electronic government (e-Gov). Document research was conducted in the sport e-gov systems of the ten member-countries. Data analysis was based on sports dimensions that guide State actions and e-Gov according to their levels of information, communication, service and participation. The results indicated that several interests lead the State to intervene in sports, information is placed at different levels of quality and quantity in each country. and democratic control is still limited.
Palabras clave Políticas Públicas. Deportes.

Acceso a la información.
Resumen: Este estudio tuvo como objetivo discutir la gestión deportiva en los países del Mercosur desde de la óptica de los gobiernos electrónicos (e-Gob). Se realizó investigación documental en los e-Gob de deporte de los diez países del Mercosur. Los datos se analizaron desde las dimensiones del deporte que guían las acciones del Estado y los e-Gob desde sus niveles de información, comunicación, servicio y participación. Los resultados indicaron que son diversos los intereses que llevan al Estado a intervenir en el deporte, que la información se coloca en diferentes niveles de calidad y cantidad en cada país y que el control democrático aún es limitado.
* Universidade do Estado da Bahia. Salvador, BA, Brasil.

E-mail:larissa_guimaraes@yahoo.com.br.

Recebido em: 02-04-2015 Aprovado em: 23-07-2015 (c) (i) () Licence 


\section{GLOBALIZAÇÃO, E-GOV E CIDADANIA}

São múltiplas as interpretações relativas à globalização, pois, de fato, estamos diante de um fenômeno que acolhe antagônicas avaliações. Dentre as características mais recorrentes, é possível reconhecer circulação instantânea de informações: ampliação dos estudos no âmbito da genética e formação de blocos econômicos interdependentes de mercados físicos e financeiros em nível mundial.

O processo de globalização, impulsionado pelo grande capital, vem desenvolvendo especialmente dois campos substantivos: o financeiro e o cultural. No primeiro recorte, os processos conjugam esforços da informática e das telecomunicações e encontram, no sistema financeiro, condições políticas e técnicas de circulação rápida do dinheiro e manutenção da histórica concentração da renda. Tal desenvolvimento de operações financeiras penetra no sistema de diversos países do mundo, tomando, como base, dois movimentos: multinacionalização e transnacionalização bancárias, como afirma Santos (1996, p. 166):

0 processo de multinacionalização bancária corresponde à penetração dos bancos no sistema financeiro de outros países e à utilização de uma rede mundial de agências pelos bancos comerciais. Daí derivam um crescimento considerável das atividades bancárias fora dos países de origem dos bancos e um crescimento ainda mais notável do lucro obtido no exterior. [...] 0 processo de transnacionalização bancária se caracteriza pelo crescimento e emergência de várias praças e centros financeiros internacionais.

A globalização econômica, ao movimentar grandes cifras, diariamente, no mercado financeiro, garante a livre circulação do capital, afirma a vocação reguladora da economia internacional e busca influenciar no destino da renda e do trabalho (LEIRO, 2001). Ao lado das referidas movimentações financeiras, com evidente impacto no mundo do trabalho, importa refletir sobre tais questões, no campo da cultura. Para lanni (1998), a globalização pode ser vista não apenas como um processo político-econômico, mas também sociocultural, que compreende tanto problemas demográficos como ecológicos, religiosos, de gênero, linguísticos e outros.

Subjazem aos campos financeiro e cultural as mudanças provocadas pelos processos de globalização no papel do Estado, notadamente nas políticas públicas que exigem novas formas de gestão. O questionável ideário do Estado mínimo coloca para os governos a necessidade de reduzir seus gastos e modernizar-se administrativamente, prezando pela transparência, eficiência, flexibilidade e agilidade das estruturas organizacionais. Importa, no entanto, reafirmar o papel estratégico do Estado no fortalecimento da democracia, na garantia dos direitos sociais, incluindo o acesso a educação, saúde, segurança, lazer e esporte.

Neste ínterim, reconhecer o esporte como direito de cada um, em tempos de capital globalizado, requer esforços para identificar os interesses que mobilizam as gestões públicas a intervir na área esportiva. Assim como cabe refletir criticamente acerca da equação que intenta inserir nossa sociedade desigual na realidade dos progressos tecnológicos e na chamada sociedade da informação.

Um dos meios para modernização da gestão pública está na inovação das gestões a partir das TIC, mais especificamente, através dos e-Gov. Martinuzzo (2008a, p. 70) refere-se ao e-Gov como: "possibilidade histórica de mediação sociopolítica e de ação governamental 
recém-constituída. [...] que trouxe novas possibilidades de comunicação e interfaces entres governos e sociedade".

Podemos considerar os e-Gov como documentos dinâmicos e plataformas eletrônicas potenciais de difusão formal dos deveres do Estado, direitos sociais e controle democrático. É espaço/tempo contemporâneo capaz de promover a interação entre cidadãos e governos públicos. No entanto, Martinuzzo (2008b) nos alerta que se deve considerar ainda que a implantação de e-Gov em países do Cone Sul fez parte de estratégias mais amplas e globais, com implicações na reestruturação dos Estados, cujo desenvolvimento se deu relativamente de modo consoante com o cenário neoliberal do contexto analisado.

Nesta perspectiva, foi empreendido um estudo exploratório que, na primeira etapa da investigação, teve a intenção de discutir a gestão pública do esporte nos países do Mercado Comum do Sul (Mercosul), pela lente de seus e-Gov.

\section{ESPORTE COMO DIREITO SOCIAL E SUAS RELAÇÕES COM O ESTADO}

Para ampliar o debate que restringe a cidadania ao papel do Estado em "conceder direitos", ou, como pensam os liberais, do "direito à propriedade privada", a reconhecemos como conquista maior de direitos, consagrada na consignação de "uma qualidade conquistada na prática e fundamento da construção de uma democracia participativa, [...] campo de forças em que direitos e deveres são ligados por lutas sociais"'.

Nesta perspectiva, a cidadania está posta, para além de eventuais concessões, como conquista da sociedade civil2 e diz respeito tanto a direitos quanto a deveres. É caracterizada pelo conflito, por tratar de lutas que trazem o cerne das desigualdades sociais e a busca por melhores condições de vida, no seio da contraditória sociedade capitalista. Portanto, ao trazer o esporte como direito social, estamos nos reportando ao seu entendimento como construção histórica e conquista humana.

Tomando o esporte como direito e necessidade humana, deve-se questionar para quais necessidades o esporte foi criado, pois, segundo Castellani Filho (2008), a produção humana busca atender determinadas necessidades sociais, que são estabelecidas ao longo da edificação societária.

Para tanto, é preciso reconhecer algumas características imbricadas na gênese do "esporte moderno". Esse fenômeno surge na ambiência da cultura europeia, por volta do século XVIII e se desenvolve sob a influência da Revolução Industrial. A esportivização dos elementos da cultura corporal na sociedade inglesa modificou os jogos, antes populares, em práticas marcadas por competição, rendimento, record, racionalização e cientifização do treinamento (BRACHT, 2005). Tais características são reafirmadas por Castellani Filho (2008, p. 132) quando discute o esporte "enquanto manifestação humana surgida e desenvolvida na sociedade moderna sob o capitalismo industrial".

Bracht (2005) argumenta que são distintos os interesses, intencionalidades e objetivos que podem levar o Estado a intervir no esporte. Os países em desenvolvimento referenciam-se nos países do primeiro mundo em duas ações fundamentais: 1âa: de afirmação nacional pelo

1 FAVERO, Celso Antônio. Apresentação da disciplina Políticas Públicas Sociais e Setoriais: Texto para debate. Universidade do Estado da Bahia, Salvador, 2010, p. 7.

2 Tomamos aqui o conceito de Gramsci, que entende "a sociedade civil como 'parte orgânica' do Estado, como âmbito dotado de especificidade, mas somente compreensível se integrado a uma totalidade histórico-social” (NOGUEIRA, 2003, p. 187). 
esporte, em âmbito internacional; 2ª̃.: de "preservação da saúde da população" e "melhoria da qualidade de vida", como formas de compensar os problemas da vida urbana.

Por isso, Linhales (2001) afirma que o esporte como instituição social está politizado. Sua trajetória é marcada por vários resultados que provêm de conflitos entre campos antagônicos, tendo o Estado como importante protagonista institucional. A disputa acontece pelas possibilidades de afirmação e legitimidade dessas intencionalidades num contexto que envolve Estado e sociedade e requer melhor compreensão acerca da particularidade do esporte como direito de todos e como política de Estado.

\subsection{0 esporte como objeto de políticas públicas}

$\mathrm{Na}$ tentativa de conceituar as políticas públicas tomamos Favero, ${ }^{3}$ quando as define como ações e reações do Estado em resposta a demandas da sociedade. $O$ autor acrescenta que elas não se dão apenas pelas relações do Estado com a sociedade civil, pois a economia e as tradições histórico-culturais também exercem influência.

Para Behring (2008) elas não significam necessariamente a diluição dos conflitos sociais, mas um importante terreno de luta de classes, que, no contexto neoliberal, vive o paradoxo da reivindicação por melhores condições de vida, em um cenário de corte de gastos públicos.

No caso específico das políticas sociais, a autora indica que tanto a variedade, a cobertura universal ou segmentada, como o financiamento e outros aspectos destas políticas dependem das relações entre as classes sociais e demais segmentos, assim como das condições econômicas gerais que vão interferir nas opções políticas e econômicas do poder público.

As políticas sociais acontecem dentro das relações sociais do modo de produção capitalista, quando a classe trabalhadora assume papéis políticos, tendo seu auge com a implementação do modelo de Estado do Bem-estar Social ${ }^{4}$ (BEHRING, 2008). Este ápice vai durar apenas enquanto duram os anos de ouro do capitalismo, pois a regulação econômica e social proposta não elimina as condições de produção e reprodução das desigualdades que decorrem da acumulação do capital.

Na década de 1990, começam as reformas do Estado sobre a tríade: desregulamentação/ descentralização/privatização, e logo os investimentos em políticas sociais deveriam ser reduzidos, pois o ideal neoliberal entende a democracia como liberdade de escolha dos serviços disponíveis no mercado. Têm-se o agravamento dos problemas sociais a partir da constituição do Estado mínimo em áreas consideradas essenciais, como educação, saúde, segurança pública, lazer e esporte, dando lugar a um mercado livre de interferências, que cada vez domina a vida social. Mascarenhas (2004) aponta que se antes o esporte e o lazer eram caracterizados como "antimercadoria", agora assumem posição de subordinação real ao capital.

A conformidade do esporte à lógica do consumo, através da chamada indústria do entretenimento, acaba reproduzindo também seus valores, assim, a exclusão e o distanciamento entre as classes alargam-se pela mercantilização das manifestações culturais. Para Castellani Filho (2008), essa é a síntese de uma concepção de organização social que exprime a cidadania pela capacidade consumidora do cidadão e entende as manifestações culturais como produtos susceptíveis de mercantilização.

3 FAVERO, Celso Antônio. Apresentação da disciplina Políticas Públicas Sociais e Setoriais: Texto para debate. Universidade do Estado da Bahia, Salvador, 2010.

4 Vale esclarecer que os padrões de bem-estar alcançados na Europa não foram os mesmos vividos na América Latina. 
Neste sentido, Bracht (2005) considera que as estruturas dos sistemas esportivos foram construções diretas ou induzidas pelos Estados a partir da ideia de que sua função primordial seria melhorar o desempenho da representação nacional em nível internacional. Esse fator dificulta a superação do modelo de pirâmide ao qual o esporte está submetido, nas gestões públicas, como fonte para a obtenção de resultados internacionais, sejam em capital simbólico, político ou econômico.

Desta forma, a indicação essencial para uma política pública esportiva e democrática é a superação do modelo piramidal com sua perspectiva de produzir atletas de alto rendimento. No entanto, permanece firme para a maioria dos políticos e é defendida pelos sistemas esportivos nacionais e internacionais. Ressalta-se que, além da procura por campeões, buscase uma massa de consumidores para os produtos e subprodutos do esporte espetáculo e de rendimento (BRACHT, 2005).

Contrário a esta lógica está o esporte numa perspectiva emancipatória. Para tanto, é necessário que este seja ressignificado e redimensionado, dando-lhe sentido político e significado social. O esporte, tomado como atividade de lazer, traz significados diferentes da perspectiva do esporte performance. É entendido como prática social que faz da cultura legada historicamente pela humanidade uma experiência de grande possibilidade de encontro lúdico e crítico, que deve ser ampliado e garantido como experiência comunitária de políticas públicas setoriais.

Neste intento, Bracht (2005, p. 88) defende o seu entendimento como "políticas culturais de lazer", justificando que, assim, outras manifestações da cultura corporal de movimento não necessitam ficar subordinadas ao conceito de esporte, tendo que se moldar a ele para se constituírem em objetos de atenção do poder público.

Estas ações voltadas às políticas culturais de lazer, segundo Leiro (2006), devem ir além da constatação da realidade e do objetivo de promover o relaxamento. Torna-se essencial que tais ações estejam voltadas à coletividade e à organização comunitária. Deve constituir-se numa política de lazer intersetorial e multidisciplinar que, no lugar da barbárie, promova ações formativas e ambientalmente sustentáveis à altura do nosso tempo.

\section{ABORDAGENS METODOLÓGICAS}

Tomamos como referência nesta pesquisa a abordagem dialética, por considerar os seguintes aspectos: sua implicação com o real concreto, seu reconhecimento como essencialmente contraditória e em constante transformação e seu pressuposto de que o conhecimento é sempre provisório e incapaz de esgotar a realidade a que se refere (KONDER, 1981).

O percurso da investigação foi delineado pela pesquisa documental e teve como universo investigativo os dez países que fazem parte (membros e associados) do Mercosul: a República Argentina, a República Federativa do Brasil, a República do Paraguai, a República Oriental do Uruguai, o Estado Plurinacional da Bolívia, a República do Chile, a República do Peru, a República do Equador, a República da Colômbia e a República Bolivariana da Venezuela.

As informações foram levantadas durante o segundo semestre de 2013 e o primeiro semestre de 2014. A partir das informações disponibilizadas nos e-Gov investigados foi possível realizar uma descrição das categorias que orientam a gestão do esporte e seus desdobramentos em projetos e programas. Para traçar o perfil dos e-Gov tomamos como ponto de partida a matriz desenvolvida por Martinuzzo (2008b), que elegeu quatro categorias de conteúdo na 
internet: Informação, Comunicação, Serviço e Participação/Mobilização, classificando-os entre elementar, intermediário e interativo, como segue:

Quadro 1 - Categorias de conteúdo na internet

\begin{tabular}{|l|l|l|l|}
\hline & ELEMENTAR & INTERMEDIÁRIO & INTERATIVO \\
\hline $\begin{array}{l}\text { INFORMAÇÃo } \\
\text { Ação em favor da transparência } \\
\text { e fortalecimento/suporte da } \\
\text { cidadania. }\end{array}$ & $\begin{array}{l}\text { Dados institucio- } \\
\text { nais, contatos com } \\
\text { a administração } \\
\text { (telefones, e-mails } \\
\text { e endereços). }\end{array}$ & $\begin{array}{l}\text { Publicações } \\
\text { oficiais, legisla- } \\
\text { ções, estatísti- } \\
\text { cas, avaliações, } \\
\text { programas oficiais } \\
\text { de governo. }\end{array}$ & $\begin{array}{l}\text { Customização na solicitação } \\
\text { e envio de dados de acordo } \\
\text { com interesses pessoais/ } \\
\text { coletivos/ } \\
\text { comunitários. }\end{array}$ \\
\hline $\begin{array}{l}\text { ComunICAÇÃo discursiva para prestação } \\
\text { de contas, persuasão e conven- } \\
\text { cimento político. }\end{array}$ & $\begin{array}{l}\text { Notícias } \\
\text { (press-releases, } \\
\text { com leads, foto- } \\
\text { grafias etc.) }\end{array}$ & $\begin{array}{l}\text { Artigos, resenhas, } \\
\text { reportagens. } \\
\text { Promoções, pro- } \\
\text { pagandas/anún- } \\
\text { cios institucionais. }\end{array}$ & $\begin{array}{l}\text { Uso de conteúdos citados } \\
\text { com recursos de multimídia } \\
\text { (áudio e vídeo). Agenda- } \\
\text { mento de entrevistas on-line. } \\
\text { Entrevistas on-line (chats } \\
\text { jornalísticos). }\end{array}$ \\
\hline $\begin{array}{l}\text { SERVIçO } \\
\text { Ação para qualificar e ampliar o } \\
\text { atendimento ao público (rapidez, } \\
\text { eficácia, menos custos). }\end{array}$ & $\begin{array}{l}\text { Divulgação/ infor- } \\
\text { mação, consulta } \\
\text { de andamento de } \\
\text { processos. }\end{array}$ & $\begin{array}{l}\text { Oferta de formulá- } \\
\text { rios para impres- } \\
\text { são, modificação } \\
\text { de bancos de } \\
\text { dados on-line. }\end{array}$ & $\begin{array}{l}\text { Transações que impliquem } \\
\text { pagamentos, emissão de } \\
\text { certidões legalmente válidas, } \\
\text { entregas de declarações. }\end{array}$ \\
\hline $\begin{array}{l}\text { PARTICIPAÇÃO/MOBILIZA- } \\
\text { ÇÃO } \\
\text { Ação para buscar, ampliar e } \\
\text { potencializar a influência dos } \\
\text { cidadãos no planejamento, } \\
\text { implementação, condução e ava- } \\
\text { liação das políticas e programas } \\
\text { públicos. }\end{array}$ & $\begin{array}{l}\text { E-mails, for- } \\
\text { mulários, "fale } \\
\text { conosco". }\end{array}$ & $\begin{array}{l}\text { Enquetes, pes- } \\
\text { quisas, consultas } \\
\text { públicas, ouvi- } \\
\text { doria. }\end{array}$ & $\begin{array}{l}\text { Chats para discussão de } \\
\text { temas relevantes; e sub- } \\
\text { missão de projetos de lei e } \\
\text { programas governamentais à } \\
\text { opinião pública, com espaços } \\
\text { claros para tal, prestação de } \\
\text { contas dos resultados. }\end{array}$ \\
\hline
\end{tabular}

Fonte: MARTINUZZO (2008b, p. 4-5)

A investigação privilegiou os portais identificados como e-Gov federais no portal eletrônico do Mercosul, para então chegar às pastas específicas do esporte em cada país. O presente estudo levou em consideração a presença de pelo menos dois dados indicados por Martinuzzo (2008b), para considerar o e-Gov intermediário ou interativo.

\section{POLÍTICAS PÚBLICAS DE ESPORTE NO MERCOSUL}

A internacionalização da economia e os crescentes interesses comuns da América Latina têm concorrido para a ressignificação de seus desafios globais e continentais. Subjazem a esse processo os passos para o acordo de criação de um bloco econômico interessado no fortalecimento dos países da América do Sul.

Este acordo foi criado em 1991 por quatro países da América do Sul: a República Argentina, a República Federativa do Brasil, a República do Paraguai e a República Oriental do Uruguai, aos quais mais tarde se uniu a República Bolivariana da Venezuela. São considerados Estados associados cinco países sul-americanos: o Estado Plurinacional da Bolívia, a República do Chile, a República da Colômbia, a República do Equador e a República do Peru 5 . O Mercosul, ao lado da política econômica comum e da livre circulação de bens e 
serviços, também se propõe a ações em distintos campos de interesse, a exemplo do Mercosul Educacional, do Mercosul Cultural e da Saúde no Mercosul.

Para que este acordo possa contribuir positivamente para a diminuição das desigualdades em seus países, o processo de cooperação internacional e de integração regional deve qualificar suas políticas públicas setoriais e edificar princípios como democracia, transparência, sustentabilidade, diversidade e universalidade.

Pode-se observar no Quadro 2, a seguir, que o lugar do esporte nas gestões públicas difere de país para país. Apenas três dos dez países investigados possuem um ministério específico para o Esporte, predominando a sua subordinação a outros setores. Marcellino (2007) afirma que o lugar em que ele deve ficar não tem muita importância, desde que se efetive como direito. Alerta, porém, que as experiências vêm demonstrando que a criação de pastas específicas traz mais autonomia administrativa e financeira, enquanto que, quando vinculado a outros setores, o esporte nem sempre consegue reconhecimento específico.

No que tange aos interesses e concepções/dimensões do esporte que orientam as ações públicas, é possível identificar algumas proximidades entre as gestões. Estas categorias são o ponto de partida na elaboração dos projetos e programas, e o enfoque a ser dado pelo Estado indica quais as intencionalidades e objetivos que se espera atingir com o esporte. A organização da gestão do esporte nos países do Mercosul está exposta no Quadro 2 a seguir:

Quadro 2 - Organização da Gestão do Esporte nos países do Mercosul|

\begin{tabular}{|c|c|c|c|}
\hline \multirow[b]{2}{*}{ PAÍSES } & \multicolumn{2}{|r|}{ ÓRGÃO GESTOR } & \multirow{2}{*}{$\begin{array}{l}\text { Categorias que orientam os } \\
\text { programas e projetos }\end{array}$} \\
\hline & MINISTÉRIO & $\begin{array}{c}\text { SECRETARIA/ INSTITUTO/ } \\
\text { DEPARTAMENTO }\end{array}$ & \\
\hline ARGENTINA & $\begin{array}{l}\text { Desenvolvimento } \\
\text { Social }\end{array}$ & Secretaria de Esporte da Nação & $\begin{array}{c}\text { Esporte Social/ Esporte de Alto } \\
\text { Rendimento }\end{array}$ \\
\hline BOLIVIA & Saúde e Esporte & Vice-Ministério do Esporte & não identificado \\
\hline BRASIL & Esporte & & $\begin{array}{l}\text { Esporte de Rendimento/ } \\
\text { Esporte Educacional/ } \\
\text { Esporte Participação }\end{array}$ \\
\hline CHILE & & Instituto Nacional de Esporte & $\begin{array}{l}\text { Alto rendimento/ Esporte } \\
\text { Massivo/ Esporte Recreativo }\end{array}$ \\
\hline COLÔMBIA & & $\begin{array}{l}\text { Departamento Administrativo do } \\
\text { Esporte, a Recreação, a Atividade Física } \\
\text { e o Aproveitamento do Tempo Livre }\end{array}$ & $\begin{array}{l}\text { Esporte/ Lazer/ } \\
\text { Atividade Física }\end{array}$ \\
\hline EQUADOR & Esporte & & $\begin{array}{l}\text { Esporte/ Educação Física/ } \\
\text { Lazer/ Esporte Adaptado }\end{array}$ \\
\hline PARAGUAI & & Secretaria Nacional de Esporte & $\begin{array}{c}\text { Esporte de Rendimento/ } \\
\text { Esporte Educacional/ } \\
\text { Esporte Social de Participação }\end{array}$ \\
\hline PERU & Educação & Instituto Peruano de Esporte & $\begin{array}{l}\text { Lazer e Promoção do esporte/ } \\
\text { Capacitação Esportiva/ } \\
\text { Esportes Federados/ Serviços } \\
\text { Biomédicos }\end{array}$ \\
\hline URUGUAI & $\begin{array}{l}\text { Turismo e } \\
\text { Esporte }\end{array}$ & Direção Nacional do Esporte & $\begin{array}{l}\text { Esporte de Alto Rendimento/ } \\
\text { Esporte Comunitário }\end{array}$ \\
\hline VENEZUELA & $\begin{array}{l}\text { Poder Popular } \\
\text { para o Esporte }\end{array}$ & & $\begin{array}{l}\text { Esporte/ Atividade Física/ } \\
\text { Educação Física }\end{array}$ \\
\hline
\end{tabular}

Fonte: Próprio autor 
$\mathrm{Na}$ Argentina, a Secretaria de Esporte da Nação pertence ao Ministério do Desenvolvimento Social, sendo seus projetos e programas guiados por duas categorias específicas: esporte social e esporte de alto rendimento. As ações da primeira área estão voltadas para os mais diversos públicos, incluindo crianças, jovens, adultos, idosos e pessoas com necessidades especiais. Envolvem atividades físicas, esportivas e culturais, focando a prática massiva nos bairros e a melhoria da qualidade de vida dos argentinos. A segunda área tem um público bem definido: atletas, para-atletas e promissores talentos esportivos. Os programas voltam-se para concessão de bolsas, prevenção e controle do doping, pesquisas aplicadas ao esporte, centros de documentação esportiva e infraestrutura esportiva para o esporte.

Na Bolívia, há um Vice-Ministério do Esporte ligado ao Ministério da Saúde, cujo enfoque de seu e-Gov está na Saúde. Foi reservado um espaço mínimo para o esporte em seu portal, tornando impossível levantar informações referentes às ações desta gestão para área esportiva. Havia apenas indicação dos objetivos para promoção da saúde, crescimento do esporte e garantia de acesso dos jovens a campos esportivos. Entendemos que esta concepção se encontra restrita e limitada, necessitando de ressignificação e redimensionamento do esporte, conforme reflexão anterior de Castellani Filho (2008).

No Brasil, temos o Ministério do Esporte, que acolhe quatro Secretarias Nacionais: Executiva; Alto Rendimento; Esporte, Educação, Lazer e Inclusão Social; Futebol e Defesa dos Direitos do Torcedor. $O$ esporte de alto rendimento focaliza grandes eventos e concessão de bolsas a atletas e para-atletas; jogos e competições nacionais e internacionais; banco de dados para identificação de futuros atletas e uma rede de centros de excelência esportiva. No esporte educacional o foco está no "Programa Segundo Tempo", que acontece no contra-turno escolar, prioritariamente para crianças e jovens em situação de risco. $O$ esporte participação/lazer tem como programa principal o "Esporte e Lazer da Cidade", oferecendo diversas modalidades para diferentes públicos. Destacam-se nesta área as redes de pesquisas - a exemplo da Rede Cedes, que busca em suas pesquisas qualificar as políticas de esporte e lazer -, o centro de documentação esportiva e o financiamento para infraestrutura e equipamentos destinados a práticas corporais.

O Instituto Nacional de Esporte do Chile está organizado a partir de três categorias: 1) Alto rendimento, com programa de iniciação e especialização em alto rendimento, concessão de bolsa e premiação de atletas profissionais; 2) Esporte Massivo, com o desenvolvimento de esporte de competição para alunos da educação básica e ensino superior, como base para a construção de plataforma de talentos esportivos; 3) Esporte recreativo, com atividades físicas e esportivas para diversos públicos, com o intuito de diminuir o sedentarismo e melhorar a qualidade de vida dos cidadãos chilenos.

A Colômbia possui o Departamento Administrativo do Esporte, da Recreação, da Atividade Física e do Aproveitamento do Tempo Livre, o COLDESPORTES, que pertence à Presidência da República. Os projetos institucionais destinam-se ao alto rendimento e há competições e jogos intercolegiais e universitários; apoio financeiro aos atletas e para-atletas; jogos olímpicos e paralímpicos nacionais. No campo do lazer são realizados jogos recreativos e esportes comunitários para toda a população e para grupos específicos: população em vulnerabilidade, idosos e pessoas com deficiência. Desenvolve-se o Programa Atividade Física na vida diária, que objetiva a prática regular do exercício para a melhoria da saúde, da qualidade de vida e do bem-estar. 
O Ministério do Esporte do Equador organiza suas ações em quatro áreas: 1) Esporte: existe um Plano de apoio ao alto rendimento; 2) Educação Física: distribuem material esportivo em escolas e desenvolvem competições estudantis; 3) Lazer: desenvolvem o Projeto "Equador exercita-se e vive saudável" no esporte, que objetiva reduzir o sedentarismo no país, através de terapia de dança e exercícios aeróbicos, que acontecem em locais públicos; 4) Esporte Adaptado: presta-se apoio a para-atletas.

O órgão responsável pelo esporte no Paraguai é a Secretaria Nacional do Esporte. Segundo o Plano Nacional para o Desenvolvimento do Esporte deste país, são três categorias que orientam suas ações: Esporte de Rendimento, Esporte Educacional e Esporte Social de Participação. No entanto, só foi possível identificar seu foco no alto rendimento, com apoio a federações esportivas e a realização de jogos escolares.

O Instituto Peruano de Esporte tem estrutura organizacional baseada em quatro áreas que dão nomes a seus departamentos e orientam seus projetos e programas: Direção Nacional de Recreação e Promoção do Esporte ${ }^{7}$; Direção Nacional de Capacitação e Técnica Esportiva, que possui programas de capacitação de agentes esportivos e de formação técnica para atletas escolares e universitários; Direção Nacional de Esportes Federados, que desenvolve programas de apoio aos atletas, formação técnica de novos talentos e manutenção dos centros de alto rendimento; Direção Nacional de Serviços Biomédicos, que presta assistência biomédica aos atletas. Não identificamos ações sobre atividades esportivas de caráter universal, diferente do que Linhales (2001) defende sobre o esporte imbricado à construção social do direito ao lazer.

A Direção Nacional do Esporte no Uruguai está ligada ao Ministério do Turismo e Esporte e tem suas ações organizadas de modo dual entre esporte de alto rendimento e esporte comunitário. Vale ressaltar que os projetos, programas e eventos que constam na página registram forte implicação com a Educação Física. Tal afirmação decorre da presença dos seguintes aspectos identificados no e-Gov: ensino do esporte; Comissão Nacional de Educação Física; Conselho de Educação Física; jogos escolares, dentre outros. Há a possibilidade de buscar serviços oferecidos de acordo com a seguinte categorização: crianças e jovens, adultos, idosos, pessoas com deficiência e instituições esportivas.

O Ministério do Poder Popular para o Esporte na Venezuela está em fase de construção do Plano Nacional de Esporte, Atividade Física e Educação Física. Conta com um Fundo Nacional do Esporte, cuja distribuição para projetos e programas em percentuais são: 39,35\% - infraestrutura esportiva; 22,31\% - preparação de atletas e eventos de Alto Rendimento; 20,73\% - massificação do esporte nas comunidades e Educação Física nas escolas; 6,09\% - atenção social integral ao atleta; 5,48\% - seguridade social dos atletas; 2,77\% - assistência à organização de eventos de ligas esportivas; 1,99\% - atenção social à atletas retirados de situações de vulnerabilidade; $1,28 \%$ - investimento em ciências aplicadas ao esporte em universidades.

Os dados explicitados acima indicam, de modo geral, que os países investigados ainda tratam o esporte de modo desigual e conservador, como já denunciado por Bracht (2005), tendo o alto rendimento como prioridade das ações na gestão pública. Tal concepção coaduna com o entendimento de organização social, que, para Castellani Filho (2006), toma como princípio privilegiar a mercantilização das manifestações culturais em detrimento do direito ao esporte como exercício de cidadania.

70 e-Gov do Instituto Peruano de Esporte não disponibilizou os projetos e programas desenvolvidos por esta Direção. 


\subsection{Perfil dos E-Gov do esporte no Mercosul}

Ao considerar os e-Gov como fontes de estudo de políticas públicas de esporte, reconhecemos seu potencial enquanto documento dinâmico e plataforma contemporânea para a democratização das gestões pesquisadas. Os perfis dos e-Gov de esporte serão apresentados no Quadro 3, que se refere aos países membros do Mercosul e Quadro 4, que se refere aos países associados.

Quadro 3 - Perfil dos e-Gov de esporte nos países membros do Mercosul

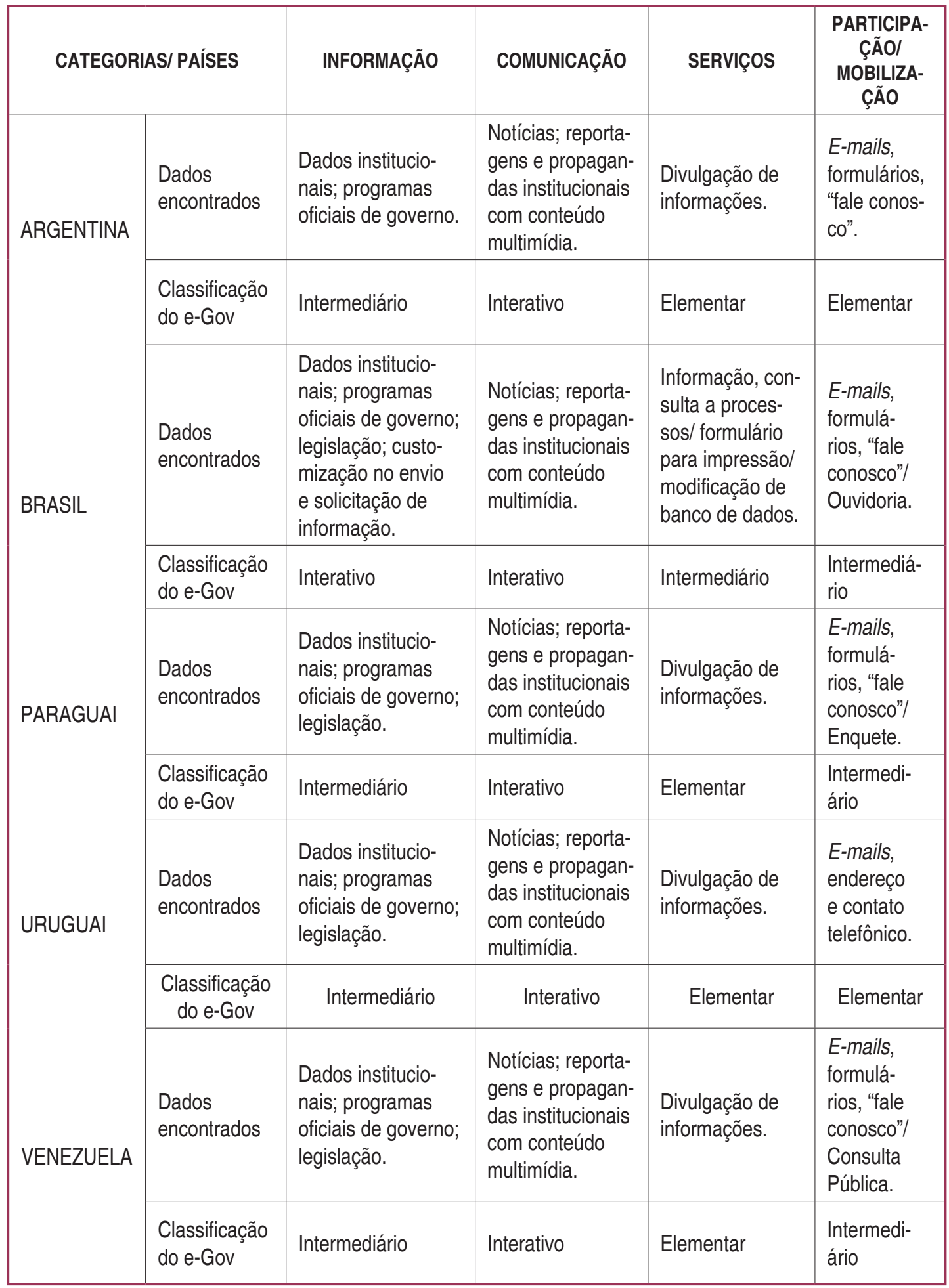


$\mathrm{Na}$ Categoria Informação, os e-Gov da Argentina, Paraguai, Uruguai e Venezuela ficaram classificados como Intermediários, com disponibilização de dados institucionais, publicidade de seus programas de governo (planos, projetos e programas) e legislação referente ao esporte no país. O Brasil teve a classificação Interativa, pois, além dos elementos já especificados, possibilita a customização no envio e solicitação de informações.

Quanto à Comunicação, todos os países do Quadro 3 são interativos, possuem notícias, reportagens, propagandas institucionais e utilizam recursos multimídia (áudio e vídeo).

Na prestação de Serviços oferecida pelos portais investigados, a Argentina, o Paraguai, - Uruguai e a Venezuela ficaram na categoria Elementar, pois se restringem à divulgação de informações, enquanto que o Brasil é considerado Intermediário, por disponibilizar consulta a processos, formulário para impressão e modificação de banco de dados.

$\mathrm{Na}$ Categoria Participação/Mobilização, a Argentina e o Uruguai foram qualificados como Elementares, por ter como único canal de interação o e-mail e a interface "fale conosco". Os demais países foram classificados como Intermediários, e se diferenciaram entre si pelo instrumento de participação/mobilização disponibilizado: o Brasil com a Ouvidoria, o Paraguai com Enquete sobre seu e-Gov e a Venezuela com o uso da Consulta Pública sobre o Plano Nacional de Esporte, Atividade Física e Educação Física.

Quadro 4 - Perfil dos e-Gov de esporte nos países associados do Mercosul

\begin{tabular}{|c|c|c|c|c|c|}
\hline \multicolumn{2}{|c|}{ CATEGORIAS/ PAÍSES } & \multirow{2}{*}{$\begin{array}{c}\text { INFORMAÇÃO } \\
\text { Dados } \\
\text { institucionais. }\end{array}$} & \multirow{2}{*}{$\begin{array}{c}\text { COMUNICAÇÃO } \\
\text { Não } \\
\text { identificado*. }\end{array}$} & \multirow{2}{*}{$\begin{array}{c}\text { SERVIÇOS } \\
\text { Não } \\
\text { identificado*. }\end{array}$} & \multirow{2}{*}{$\begin{array}{c}\text { PARTICIPAÇÃOI } \\
\text { MOBILIZAÇÃO }\end{array}$} \\
\hline & $\begin{array}{c}\text { Dados } \\
\text { encontrados }\end{array}$ & & & & \\
\hline & $\begin{array}{c}\text { Classificação } \\
\text { do e-Gov }\end{array}$ & Elementar & Elementar & Elementar & Elementar \\
\hline \multirow[t]{2}{*}{ CHILE } & $\begin{array}{c}\text { Dados } \\
\text { encontrados }\end{array}$ & $\begin{array}{c}\text { Dados } \\
\text { institucionais; } \\
\text { programas } \\
\text { oficiais de } \\
\text { governo; } \\
\text { legislação; } \\
\text { customização } \\
\text { no envio e } \\
\text { solicitação de } \\
\text { informação. }\end{array}$ & $\begin{array}{c}\text { Notícias; } \\
\text { reportagens e } \\
\text { propagandas } \\
\text { institucionais } \\
\text { com conteúdo } \\
\text { multimídia. }\end{array}$ & $\begin{array}{c}\text { Informação, } \\
\text { consulta a } \\
\text { processos/ } \\
\text { formulário } \\
\text { para } \\
\text { impressão/ } \\
\text { modificação } \\
\text { de banco de } \\
\text { dados. }\end{array}$ & $\begin{array}{c}\text { E-mails, formulários, } \\
\text { "fale conosco"/ } \\
\text { Ouvidoria. }\end{array}$ \\
\hline & $\begin{array}{c}\text { Classificação } \\
\text { do e-Gov }\end{array}$ & Interativo & Interativo & Intermediário & Intermediário \\
\hline \multirow[t]{2}{*}{ COLÔMBIA } & $\begin{array}{c}\text { Dados } \\
\text { encontrados }\end{array}$ & $\begin{array}{c}\text { Dados } \\
\text { institucionais; } \\
\text { programas } \\
\text { oficiais de } \\
\text { governo; } \\
\text { legislação. }\end{array}$ & $\begin{array}{l}\text { Notícias; } \\
\text { reportagens e } \\
\text { propagandas } \\
\text { institucionais } \\
\text { com conteúdo } \\
\text { multimídia. }\end{array}$ & $\begin{array}{c}\text { Informação, } \\
\text { consulta a } \\
\text { processos/ } \\
\text { modificação } \\
\text { de banco de } \\
\text { dados. }\end{array}$ & $\begin{array}{c}\text { E-mails, formulários, } \\
\text { "fale conosco"/ } \\
\text { Ouvidoria/ Chats. }\end{array}$ \\
\hline & $\begin{array}{c}\text { Classificação } \\
\text { do e-Gov }\end{array}$ & Intermediário & Interativo & Intermediário & Intermediário \\
\hline
\end{tabular}

Continua na próxima página... 
Continuação do quadro...

\begin{tabular}{|c|c|c|c|c|c|}
\hline \multirow[t]{2}{*}{ EQUADOR } & $\begin{array}{c}\text { Dados } \\
\text { encontrados }\end{array}$ & $\begin{array}{c}\text { Dados } \\
\text { institucionais; } \\
\text { programas } \\
\text { oficiais de } \\
\text { governo; } \\
\text { legislação. }\end{array}$ & $\begin{array}{c}\text { Notícias; } \\
\text { reportagens e } \\
\text { propagandas } \\
\text { institucionais } \\
\text { com conteúdo } \\
\text { multimídia. }\end{array}$ & $\begin{array}{l}\text { Informação/ } \\
\text { formulário } \\
\text { para } \\
\text { impressão. }\end{array}$ & $\begin{array}{l}\text { E-mails, formulários, } \\
\text { "fale conosco". }\end{array}$ \\
\hline & $\begin{array}{c}\text { Classificação } \\
\text { do e-Gov }\end{array}$ & Intermediário & Interativo & $\begin{array}{l}\text { Intermediário } \\
\text { com restrição }\end{array}$ & Elementar \\
\hline \multirow[t]{2}{*}{ PERU } & $\begin{array}{c}\text { Dados } \\
\text { encontrados }\end{array}$ & $\begin{array}{c}\text { Dados } \\
\text { institucionais; } \\
\text { programas } \\
\text { oficiais de } \\
\text { governo; } \\
\text { legislação. }\end{array}$ & $\begin{array}{c}\text { Notícias; } \\
\text { reportagens e } \\
\text { propagandas } \\
\text { institucionais } \\
\text { com conteúdo } \\
\text { multimídia. }\end{array}$ & $\begin{array}{l}\text { Divulgação de } \\
\text { informações. }\end{array}$ & $\begin{array}{l}\text { E-mails, formulários, } \\
\text { "fale conosco". }\end{array}$ \\
\hline & $\begin{array}{c}\text { Classificação } \\
\text { do e-Gov }\end{array}$ & Intermediário & Interativo & Elementar & Elementar \\
\hline
\end{tabular}

Fonte: Próprio autor

* Na Bolívia não há um e-Gov específico para o Vice-Ministério do Esporte. Os dados foram levantados no e-Gov do Ministério da Saúde e Esporte, cujo foco situa-se na primeira área de intervenção.

Dentro da Categoria Informação, o e-Gov da Bolívia ficou classificado como Elementar, já que só foi possível identificar dados referentes à missão do Vice-Ministério do Esporte e ao perfil do seu gestor. A Colômbia, o Equador e o Peru disponibilizam dados institucionais, programas oficiais de governo e legislação e tiveram seus e-Gov considerados Intermediários. O Chile ficou classificado como Interativo, por acrescentar em seu portal a customização no envio e solicitação de informações.

Na Comunicação, o e-Gov da Bolívia foi avaliado como Elementar, pois não são disponibilizadas informações referentes ao esporte. Os outros países foram entendidos como Interativos, pois disponibilizam notícias, reportagens e propagandas institucionais, com conteúdo multimídia.

Quanto aos Serviços, a Bolívia e o Peru foram considerados Elementares, já que estes inexistem no e-Gov do primeiro e se resumem à divulgação de informação no segundo. $A$ Colômbia foi classificada como Interativa, pois, além de divulgar informações, oferece consulta a processos e modificação de banco de dados. O Equador foi considerado Interativo com restrição por possuir apenas um item desta classificação: a disponibilização de formulários para impressão. O Chile foi avaliado como Intermediário, por reunir os referidos serviços.

Na Categoria Participação/Mobilização os e-Gov da Bolívia, do Equador e do Peru classificaram-se enquanto Elementares, já que colocam à disposição dos internautas/cidadãos apenas seus endereços eletrônicos ou a interface "fale conosco". O Chile oferece ainda a Ouvidoria como instrumento de participação social e foi considerado Intermediário, assim como a Colômbia, que acrescenta o chat como canal de interlocução entre governo e sociedade civil.

A partir do exposto, consideramos que os dados encontrados nos e-Gov que tratam da gestão do esporte no Mercosul se aproximaram dos dados encontrados por Martinuzzo (2008b) sobre os portais federais de e-Gov no Mercosul, já que o conteúdo da informação nestes países do Cone Sul trouxe como foco o trâmite burocrático da administração pública e os serviços oferecidos, a comunicação se caracterizou como unilateral e os canais de participação/ mobilização ainda são limitados e limitantes. Para o autor, as telinhas revelam que ainda são 
tímidas as experiências com e-Gov por parte dos poderes públicos no Mercosul e convoca governos e sociedade para potencializar criticamente o e-Gov, superar o entendimento do usuário do serviço público como clientes e afirmá-lo como sujeito de direito.

\section{CONSIDERAÇÕES FINAIS}

Fica evidente que são diversos os interesses que levam o Estado a intervir no esporte. Pode-se afirmar também que o lugar que este ocupa nas gestões públicas e em sua organização determina os desdobramentos em políticas públicas.

Pelas características históricas, políticas e econômicas dos países analisados, os resultados encontrados fortalecem o entendimento de Bracht (2005), ao afirmar que os países em desenvolvimento absorveram, dos países do primeiro mundo, dois direcionamentos para suas ações no esporte: o primeiro, de afirmação nacional, pela visibilidade em âmbito internacional, e, o segundo, de "preservação da saúde da população" e "melhoria da qualidade de vida", como forma de equilibrar os problemas da vida urbana.

É digna de nota a atenção predominante ao esporte de alto rendimento, em todos os países do Mercosul. Um fascínio governamental que provavelmente decorre do interesse ordinário de atrair apoios simbólicos e financeiros através das marcas e da visibilidade extraordinária alcançada em diferentes espaços midiáticos.

Quanto aos e-Gov, identificou-se que, em sua maioria, oferecem como serviço principal notícias e informações referentes ao esporte, que variam em quantidade e qualidade entre os países. Predomina como meio de interação com o cidadão a possibilidade de envio de mensagens pelo e-mail ou "fale conosco". Quanto à transparência na gestão, os e-Gov ainda precisam ser mais explorados, pois nem todos os países os utilizam como mecanismos de divulgação de suas políticas e oferta de serviços ao cidadão. No entanto, é possível perceber algumas ações positivas, que caminham em direção de governos mais democráticos e populares.

Diante dos limites, potencialidades e proximidade dos países sul-americanos, tornase importante qualificar as relações internacionais, com vistas a ampliar a cooperação e a integração do Mercosul, notadamente no âmbito das políticas públicas, que tomam o esporte e o lazer como um direito de todos, que valoriza a multidisciplinaridade como metodologia e a intersetorialidade como referência.

Sendo assim, reconhecemos a necessidade de aprofundamento do estudo em tela e a importância da socialização das experiências desenvolvidas em cada país, como desafio estratégico de fortalecimento dos vínculos culturais, científicos e tecnológicos, bem como de consolidação de gestões comprometidas com a emancipação humana e o desenvolvimento social dos povos sul-americanos.

\section{REFERÊNCIAS}

BEHRING, Elaine Rossetti. Políticas sociais: Seus fundamentos lógicos e suas circunstâncias históricas. In: GARCIA, Carla Cristina; HÚNGARO, Edson Marcelo; DAMASCENO, Luciano Galvão (Org.). Estado, política e emancipação humana: lazer, educação, esporte e saúde como direitos sociais. Santo André: Alpharrabio, 2008. p. 61-66. 
BOLÍVIA. Ministério de Deportes. Disponível em: < http://www.mindeportes.gob.bo/ > Acesso em: 19 set. 2013.

BRACHT, Valter. Sociologia crítica do esporte: uma introdução. 3. ed. Ijuí: Ed. Unijuí, 2005.

BRASIL. Ministério do Esporte. Disponível em: <http://www.esporte.gov.br/>. Acesso em: 19 set. 2013.

BRASIL.Controladoria Geral da União. Transparência Pública, 2010. Disponível em: <http://www3. transparencia.gov.br/TransparenciaPublica/origem/index.html>. Acesso em: 26 set. 2013.

CASTELLANI FILHO, Lino. O estado brasileiro e os direitos sociais: o esporte. In: GARCIA, Carla Cristina; HÚNGARO, Edson Marcelo; DAMASCENO, Luciano Galvão (Org.). Estado, política e emancipação humana: lazer, educação, esporte e saúde como direitos sociais. Santo André: Alpharrabio, 2008. p. 129-144.

CHILE. Ministerio del Deporte. Instituto Nacional de Deportes. Disponível em: $<$ http://www.ind.cl/ Pages/inicio.aspx>. Acesso em: 27 set. 2013.

COLÔMBIA. Ministério da Cultura. Instituto Colombiano del Deporte. Disponível em: <http://www. coldeportes.gov.co>. Acesso em: 27 set. 2013.

ECUADOR. Ministério del Deporte. Disponível em: <http://www.deporte.gob.ec>. Acesso em: 27 set. 2013.

IANNI, Octavio. As ciências sociais na época da globalização. Revista Brasileira de Ciências Sociais, São Paulo, v. 13, n. 37, p.33-41, jun. 1998.

KONDER, Leandro. 0 que é dialética? 25. ed. São Paulo: Brasiliense, 1981.

LEIRO, Augusto Cesar Rios. Educação, lazer e cultura corporal. Revista Presente, Salvador, v. 53, p. 47-53, 2006.

LEIRO, Augusto César Rios. Lazer e educação nos parques públicos de Salvador: encontro de sujeitos em espaços de cidadania. 2001. Dissertação (Mestrado) - Programa de Pós-Graduação em Educação, Universidade Federal da Bahia, Salvador, 2001.

LINHALES, Meily Assbú. Jogos da política, jogos do esporte: subsídios à reflexão sobre políticas públicas para o setor esportivo. In: MARCELLINO, Nelson Carvalho. (Org.). Lazer e esporte: políticas públicas. Campinas: Autores Associados, 2001. p. 31-56.

MARCELLINO, Nelson Carvalho. Políticas públicas de esporte e lazer: o papel do poder público e do terceiro setor. In: MENDES, Maria Isabel Brandão de Souza; MAIA, Lerson Fernando dos Santos; OLIVEIRA, Marcus Vinícius de Faria. Poder público, terceiro setor e controle social: interfaces na construção de políticas de esporte e lazer. Natal: CEFET-RN, 2007. p. 9-24.

MARTINUZZO, José Antônio. Governo eletrônico e crise dos cartões corporativos: a necessária conexão irrealizada. Lugar Comum, Rio de Janeiro, n. 23-24, p. 67-84, 2008a.

MARTINUZZO, José Antônio. Governo eletrônico no Mercosul: o retrato segundo os portais federais de e-Gov. Revista Eletrônica Internacional de Economia Política da Informação da Comunicación e da cultura, Aracaju, v. 10, n. 1, jan./abr. 2008b. Disponível em: < http://www.seer. ufs.br/index.php/eptic/article/view/170/145>. Acesso em: 27 set. 2013.

MASCARENHAS. Fernando. "Lazerania" também é conquista: tendências e desafios na era do mercado. Movimento, Porto Alegre, v. 10, n. 2, p. 73-90, 2004.

NOGUEIRA, Marco Aurélio. Sociedade civil, entre o político-estatal e o universo gerencial. Revista brasileira de Ciências Sociais, São Paulo, v.18, n.52, p.185-202, 2003.

PARAGUAY. Secretaria Nacional De Deporte. Acesso em: <http://www.snd.gov.py $>$. Acesso em: 19 set 2013. 
PERÚ. Instituto Peruano del Deporte. Disponível em: <http://www.ipd.gob.pe/>. Acesso em: 19 set. 2013.

SANTOS, Milton. A natureza do espaço: técnica e tempo, razão e emoção. São Paulo: Hucitec, 1996.

URUGUAY. Secretaria Nacional del Deporte. Disponível em: <http://www.deporte.gub.uy/web/index. php>. Acesso em: 25 mar. 2014.

VENEZUELA. Gobierno Bolivariano de Venezuela. Ministério del Poder popular para la juventud y el deporte. Disponível em: <http://www.mindeporte.gob.ve>. Acesso em: 25 set. 2013. 
